\title{
Fermented Dairy Products and Their Place in International Gastronomy
}

\author{
Mahendra Pal ${ }^{1, *}$, Judit Molnar ${ }^{2}$ \\ ${ }^{1}$ Narayan Consultancy on Veterinary Public Health and Microbiology, Anand-388001, Gujarat, India. \\ ${ }^{2}$ Department of Water and Environmental Sciences, Faculty of Agricultural and Food Sciences, SzéchenyiIstván University, 9200 \\ Mosonmagyaróvár, Győr-Moson-Sopron county, Hungary.
}

\begin{abstract}
How to cite this paper: Mahendra $\mathrm{Pal}$ Judit Molnar. (2022) Fermented Dairy Products and Their Place in International Gastronomy. International Journal of Food Science and Agriculture, 6(1), 1-3. DOI: $10.26855 /$ ijfsa.2022.03.001

Received: December 2, 2021

Accepted: December 25, 2021

Published: January 6, 2022

*Corresponding author: Mahendra Pal, Narayan Consultancy on Veterinary Public Health and Microbiology, Anand-388001, Gujarat, India.

Email: palmahendra2@gmail.com
\end{abstract}

\begin{abstract}
Fermented foods also known as functional foods are recognized to the mankind since ancient times due to their several health benefits. Nowadays, learning about the health effects of functional foods is becoming increasingly important globally. Outstanding among these products is the physiological effect of fermented dairy products like yoghurt, and cheese on the human body. The beneficial properties of the lactic acid bacteria found in them mostly stimulate the functioning of the gastrointestinal tract, immune system, and contributing to the well-being. That is why they are also part of many special diets, such as Mediterranean diet. Some of the fermented dairy products, such as cheese, and yoghurt are easily available globally where as shrikhand and paneer are very popular fermented foods in India. These products are excellent sources of protein, calcium, and other nutrients. Moreover, the presence of live microbs in these products is considered accountable for a number of health benefits. The epidemiological evidences indicated that consumption of yogurt in diet is usually related to reduce the risk of type 2 diabetes that affects millions of people worldwide. The manuscript also discusses the importance of some of the fermented dairy products, such as cheese, yogurt, kefir, cottage cheese, paneer, and shrikhand, and their effects on human health. In addition, it describes the most important fermented dairy products in international gastronomy. Furthermore, we would like to contribute the knowledge of the readers and the protection of their health as well.
\end{abstract}

\section{Keywords}

Fermented dairy products, probiotics, functional foods, healthy diet, healthy life, international gastronomy

\section{Introduction}

Fermented foods (functional foods) play a prominent role in the diet consumed by people throughout the world. The concept of these products is not uniform, but their positive physiological effect and the substantiation of research results support their practical usefulness [1]. Several ways of grouping functional foods are known (effect on health, differentiation according to their origin). In addition, to their development opportunities, these will be given a prominent role in scientific research [2]. Thus, in addition to the most important staple foods (cereals, vegetables and fruits, meat, fish, milk and dairy products), functional foods also include technological processes that provide newly developed (for example: fortified) products. Fermentation, which has been used since ancient times, is also a preferred method in the food industry worldwide [3]. This process has made it possible to produce fermented dairy products, which are among the healthiest foods [4]. 
Fermented dairy products have outstanding physiological benefits, including effects on the gastrointestinal tract and support of the immune system [5]. Fermented dairy products are not only healthy due to their texture and taste, but also play a prominent role in international gastronomy. Among others, cheeses, kefir, cottage cheese, yogurt are foods recognized in the Mediterranean diet [6]. In our manuscript, we present the properties of the most important fermented dairy products, such as cheese, yogurt, kefir, cottage cheese, paneer, and shrikhand, which have a prominent place among functional foods. Furthermore, we also would like to present their physiological effect and their role in international gastronomy. We hope that we can contribute to the health of readers and a better understanding of fermented dairy products as well.

\section{Production of fermented dairy products and their physiological role in the human body}

The production of fermented dairy products is based on the activity of microorganisms (lactic acid bacteria and yeasts). The properly prepared milk with the help of useful microbes (under the right conditions: temperature, anaerobic conditions, $\mathrm{pH}$, fermentation time and so on) can be used to make fermented dairy products, which provide an outstanding gastro-experience [4]. Most of the lactose is also used in their production, which also plays a role in facilitating digestive processes. Furthermore, due to their useful content values such as complex protein (casein) or vitamins, minerals, they also contribute to maintaining health. Lactose breakdown makes it easier for milk-sensitive people to digest fermented dairy products. Furthermore, these products, due to their useful protein content, reduce osteoporosis and help children develop. Thanks to their beneficial microorganism content, they also improve and regenerate the functioning of the intestinal system. At the same time, they stimulate the immune system [7, 8].

\section{The role of cheese, yogurt, kefir, cottage cheese, paneer and Shrikhand in international ga- stronomy}

$>$ Cheese: Cheeses are a popular addition to the Mediterranean diet, served mostly with quality fruits and wines. They can be a popular addition to fried foods, but they can also be an excellent gastronomic experience when grilled. Their consumption is recommended due to their high fat content [9].

$>$ Yogurt: When making homemade yogurt, the natural version is most preferred. It can also be used for frying and cooking with fruits, green spices and natural sweeteners [10].

> Kefir: Kefir is a fermented milk drink that is made from mesophilic symbiotic culture (bacteria and yeast). Kefir fermentation process produces good bacteria to help balance gastrointestinal system [11].

$>$ Cottage cheese: Perfect dessert supplements but in low-fat form with sweetener. Furthermore, cottage cheese can be mixed into other foods in a variety of ways [12].

> Paneer: Paneer is a popular, well-known heat and acid-coagulated milk product in Indian Sub-continent. It is rich in calcium, protein and helps in several bodies function [13].

$>$ Shrikhand: Shrikhand is a delicious, traditional fermented dairy product in India. This fermented product is manufactured by blending Chakka, and it contains sugar, cream, nuts, fruits, cardamom, saffron and other spices as well. Furthermore, it has several useful nutritional and therapeutic benefits [14].

\section{Conclusion}

The manuscript focuses on fermented dairy products produced with the help of beneficial microorganisms (more yeasts and lactic acid bacteria) as functional foods. Fermented dairy products including cottage cheese, yogurt, kefir, cheeses, paneer and shrikhand play a prominent role in maintaining the normal intestinal flora and protecting the immune system. Furthermore, these products can be consumed in case of lactose intolerance (in case of individual tolerance), if there are not other intestinal diseases. Fermented dairy products play an important role in various diets, such as the Mediterranean diet. Cottage cheese, yoghurt, kefir, cheeses, paneer, and shrikhand are prominent players in international gastronomy. In addition, they can be eaten fried and cooked form as well. They can also be combined well with fruits and vegetables. We hope that introducing the properties of fermented dairy products improve the knowledge and health of readers.

\section{Acknowledgements}

The authors are very thankful to Prof. Dr. R. K. Narayan for his suggestions during the preparation of manuscript and Anubha Priyabandhu for computer help. This paper is dedicated to the scientists who made important contribution in the field of food science. 


\section{Contribution of authors}

All the authors contributed equally. They read the final version, and approved it for the publication.

\section{Conflict of interest}

The authors declare that they do not have conflict of interest.

\section{Source of financial grant}

There was no financial support for this manuscript.

\section{References}

[1] Alongi, M. and Anese, M. (2021). Re-thinking functional food development though a holistic approach. Journal of Functional Foods, 81: 1-13.

[2] Rashwan, A. K., Karim, N., Shishir, M. R. I., Bao, T., Lu, Y., and Chen, W. (2020). Jujube fruit: A potential nutritious fruit for the development of functional food products. Journal of Functional Foods, 75: 1-16.

[3] Wu, Q., Zhu, Y., Fang, C., Wijffels, R. H. and Xu, Y. (2021). Can we control microbiota in spontaneous food fermentation?-Chinese liquor as a case example. Trend sin Food Science \& Technology, 110: 321-331.

[4] García-Burgos, M., Moreno-Fernández, J., Alférez, M. J. M., Díaz-Castro, J., and López-Aliaga, I. (2020). New perspectives in fermented dairy products and their health relevance. Journal of Functional Foods, 72: 1-11.

[5] Guimarães, J. T., Balthazar, C. F., Scudino, H., Pimentel, T. C., Esmerino, E. A., Ashokkumar, M., Freitas, M. Q., and Cruz, A. G. (2019). High-intensity ultrasound: A novel technology for the development of probiotic and prebiotic dairy products. Ultrasonics- Sonochemistry, 57: 12-21.

[6] Tsigalou, C., Paraschaki, A., Karvelas, A., Kantartzi, K., Gagali, K., Tsairidis, D., and Bezirtzoglou, E. (2021). Gut microbiome and Mediterranean diet in the context of obesity. Current knowledge, perspectives and potential therapeutic targets. Metabolism Open, 9: 1-9.

[7] Gomi, A., Iino, T., Nonaka, C., Miyazaki, K., and Ishikawa, F. (2015). Health benefits of fermented milk containing Bifidobacterium bifidum YIT 10347 on gastric symptoms in adults. Journal of Dairy Science, 98: 2277-2283.

[8] Molnár, J. (2020). Effects of probiotics on maintaining human Health. Nutrition and Food Science International Journal, 10: 1-2.

[9] Fiol, C., Prado, D., Mora, M., and Alava, J. I. (2016). Nettle cheese: Using nettle leaves (Urtica dioica) to coagulate milk in the fresh cheese making process. International Journal of Gastronomy and Food Science, 4: 19-24.

[10] Aryana, K. J. and Olson, D. W. (2017). A 100-Year Review: Yogurt and other cultured dairy products. Journal of Dairy Science, 100: 9987-10013.

[11] Hatmal, M. M., Nuirat, A., Zihlif, M. A., and Taha, M. O. (2018). Exploring the influence of culture conditions on kefir’s anticancer properties. Journal of Dairy Science, 101: 3771-3777.

[12] Araújo, E. A., Carvalho, de A. F., Leandro, E. S., Furtado, M. M., and Moraes, de C. A. (2010). Development of a symbiotic cottage cheese added with Lactobacillus delbrueckii UFV H2b20 and inulin. Journal of Functional Foods, 2: 85-89.

[13] Pal, M. (2019). Paneer: A very popular milk product in Indian Sub-continent. Beverage and Food World, 46: 23-25.

[14] Pal, M. and Devrani, M. (2018). Shrikhand: A delicious fermented dairy product of India. Beverage and Food World, 45: 39-40. 